\title{
Impairments, mastery, and loneliness. A prospective study of loneliness among older adults
}

\author{
Magnhild Nicolaisen ${ }^{1}$ and Kirsten Thorsen ${ }^{1,2,3}$ \\ 1) Ageing and Health, Norwegian Centre for Research, Education and Service Development \\ 2) Norwegian Social Research (NOVA) \\ 3) Buskerud University College, Norway \\ Correspondence: Magnhild NicolaisenＥ-mail: magnhild.nicolaisen@aldringoghelse.noＴelephone: +47 23016144
}

\begin{abstract}
Old age is commonly associated with loneliness as loss of partner and friends, retirement, deteriorating health and functional impairments may make way for loneliness. An ageing population may give rise to concern for growing numbers of lonely people. The study explores loneliness among older people 67-79 years old $(\mathrm{N}=699)$, living in their own homes, examining whether and how socio-demographic factors, subjective health, and mastery influence loneliness among people with no impairments and people with impairments. The study uses cross-sectional and longitudinal (five-year panel) data from the Norwegian Life Course, Ageing and Generation study (NorLAG), calculating the risk of loneliness at T1, and prospectively at T2. Mastery is the only factor significantly influencing the risk of loneliness both at T1 and T2, both for older people with impairments and for those without impairments. A high level of mastery is related to a lower risk of loneliness. Being married or cohabitant are related to a lower risk of loneliness, among those without impairments both at $\mathrm{T} 1$ and at $\mathrm{T} 2$, among those with impairments only at T1. Age, gender and subjective health were not independently related to loneliness at any time. The results suggest that the subjective feeling of mastery is important to avoid loneliness, both at $\mathrm{T} 1$ and prospectively at $\mathrm{T} 2 \mathrm{in}$ both groups.
\end{abstract}

\section{INTRODUCTION}

Loneliness is a universal experience as most people experience loneliness now and then. It is generally defined as a subjective experience of unsatisfactory social relations. Loneliness is a subjective experience; it is not synonymous with objective social isolation. People can be alone without being lonely, or lonely in a crowd (1-3). Old age is commonly associated with loneliness as people outlive partners and friends and exit working life. Older age is also associated with a higher risk of having impairments, which can make socializing more demanding and thus make way for loneliness. Several studies show a clear relation between impairments/ functional disability and loneliness. The association is found whether impairment is measured by general measures of daily life function (like ADL and IADL), specific physiological limitations, or limited capability of seeing or hearing, or specific diagnoses and illnesses, or the person's own subjective opinion of health or of being disabled (2-8). Also poor general health $(3,7$, 9-13), and specific diagnoses or illnesses are associated with loneliness (e.g. 3,14,15).

As the population ages (16), there are indications that people will live longer with their chronic diseases (17). These developments may cause concern for a growing number of people susceptible to loneliness. Hence, strategies of preventing and alleviating loneliness are of great interest and significance, and it is necessary to know more about factors releasing, aggravating, and alleviating loneliness. Loneliness has been linked to many aspects of life that in combination explain why some older people feel lonely. Both precipi- tating events and predisposing factors like personal characteristics, social skills, attribution styles and habitual patterns of interaction are seen as factors having a potential impact on loneliness, and are explored empirically.

Most studies on loneliness are cross sectional studies assessing associations with age, gender and health. Results from these studies are mixed for age, with some studies finding higher rates of loneliness in older age groups $(18,19)$ whereas other studies indicate loneliness being more intense in younger age groups $(20,21)$. A recent study of Victor \& Yang (22) showed that the association between loneliness and age is Ushaped. Higher prevalence of loneliness among older people may be attributable to age-related increases in risk factors, such as impairments, income, widowhood and living alone, rather than to ageing itself (3). Women tend to report higher rates of loneliness than men $(3,20,23-25)$. Loneliness is more common in people living alone $(3,7,13,20,25,26)$, and not being married $(7,11,19,27-29)$. Loneliness is also associated with having lower socio-economic status $(3,7,9,11)$. Finally, higher levels of social self-efficacy (feelings of being in control in social situations) (30), and coping selfefficacy (31) are associated with less loneliness.

Longitudinal studies of loneliness mainly show similar associations as cross-sectional studies. Poor health and poor functional capacity, marital status as single, limited social network, and living alone are associated with loneliness over time $(26,28,32,33)$. Some longitudinal studies show that loneliness increases in old age $(26,32,33)$, other studies do not $(28,34)$. There are few longitudinal studies exploring the asso- 
ciation between disability and loneliness. Jylhä (26) found that persons aged $60+$ with functional disability were more likely to report loneliness than others, and they were also more likely to become lonely in the future. Similarly, Aartsen \& Jylhä (35) reported that increased physical disabilities (rather than baseline level) was related to enhanced feelings of loneliness at follow-up among older adults aged 60-86 years at baseline. Tijhuis et al. (33), however, found that changes in limitations in activities of daily living were not related to loneliness among men aged 65-85 years at baseline. Guiaux (36) in a longitudinal study among older adults, found that a low sense of mastery predicted loneliness. Sense of mastery refers to the extent to which people feel in control of their life and environment in contrast to being fatalistic (37). Mastery is considered an important factor in "successful ageing" and crucial for maintaining functional ability in later life and cope with disabilities (38-41).

The aim of this study is to examine the extent to which socio-demographic factors, health status and mastery influence loneliness in older adults without impairments and older adults with impairments. Associations will be analyzed using cross-sectional as well as longitudinal (five-year panel) data.

\section{Methods}

\section{Data}

The study is based on panel data from the Norwegian Life Course, Aging, and Generation Study (NorLAG), i.e. on the same persons answering questions at two times. The first wave of NorLAG (T1) was conducted in 2002/3, with respondents aged 40-79 years at baseline. The second wave (T2) was conducted in 2007/8. The sample is drawn from 30 municipalities and townships from all over Norway. A combination of telephone interviews and postal questionnaires was used in both waves. At T1, a total of 5,559 persons (67\%) responded to the telephone interview and 4,149 (75\%) of these returned the postal questionnaire. The net sample of the NorLAG panel (persons interviewed at $\mathrm{T} 1$ and $\mathrm{T} 2$ ) consists of 3,774 persons, which implies that $71.6 \%$ of the respondents from wave 1 were retained at wave 2 . This corresponds to $50 \%$ of the eligible gross sample (42). This paper uses data from 699 persons aged 67-79 years who answered a global question about loneliness in telephone interview at both $\mathrm{T} 1$ $(2002 / 3)$ and T2 (2007/8). The sample includes people living outside institutions.

The loss of respondents from $\mathrm{T} 1$ to $\mathrm{T} 2$ was disproportionally distributed concerning age, health and education. Considering respondents who had died, or refused to or were not able to participate, respondents for whom we have longitudinal data at T2 are more likely to be younger, in better health and more educated than the sample at T1 (42). This kind of sample selection corresponds with panel samples in other longitudinal studies $(32,43)$.

\section{Measures}

\section{Dependent variable}

Loneliness is assessed by a single, global question: "Do you feel lonely?" Response categories are 1="often", 2="sometimes", 3="seldom" or 4="never". Although this measure has limitations $(44,45)$, it has been used in numerous studies $(3,25-29,34,46-48)$ and has been reported to have good face and predictive validity (46). A global single item question about loneliness necessarily measures loneliness as understood by the respondent, not as predefined by the researcher (26).

For purposes of statistical analysis the loneliness variable was dichotomized, with response categories "often" or "sometimes" lonely combined into 1="Lonely". Response categories "seldom" or "never" lonely are combined into $0=$ "Not lonely". This way of dichotomizing is often used in studies of loneliness (i.e. 25,34,47,48). We have classified "sometimes lonely" as "lonely" because it may be easier for people who are lonely to admit that they feel lonely sometimes than to say they feel lonely often, since being lonely carries a stigma (47).

Ancillary analyses with the loneliness variable dichotomized another way, with $1=$ "often" lonely, and $0=$ "sometimes", "seldom" or "never" lonely, have very few statistical significant results, which is probably caused by the low number of respondents feeling lonely "often" (5.7 percent of the sample feel lonely "often", while 24.0 percent "sometimes", 33.8 percent "seldom", and 36.5 percent "never" feel lonely).

Using the loneliness variable in an ordinal logistic regression analysis turned out to yield much the same result as in the binary logistic regression: in both analyses, personal mastery and partner status are predictors of loneliness, both among the group with no impairments and among those with impairments. Since the results of the ordinal regression and the binary regression analyses are very similar, and the results from the binary regressions are easier to understand, we here report the results with the dichotomized loneliness variable.

\section{Independent variables}

Mastery was measured by the Personal Mastery Scale (37). The Personal Mastery Scale has seven items, each of which is evaluated on a five-point Likert scale ranging from (1) 'strongly agree' to (5) 'strongly disagree'. The scale measures a general attitude towards the possibilities of influencing one's own life situation and focuses on control of those aspects of life that people consider personally important (49). The items are: (1) I have little control over things that happen to me; (2) What happens to me in the future mostly depends on me; (3) There is really no way I can solve some of my problems; (4) There is little I can do to change many of the important things in my life; (5) I often feel helpless in dealing with the problems of my life; (6) Sometimes I feel I'm being pushed around in life; and (7) I can do just about anything I really set my mind to 
do. An index was estimated as the mean of the seven scores, with high scores indicating high mastery (Cronbach's alpha $=0.72$ ).

Impairments are measured by an index, formed by three items. The respondents were asked if their present health condition restricted them in a) activities like moving a table, vacuum cleaning, go for a walk, or gardening, and b) walk up stairs, several floors. (Alternatives: no/yes). The third item was c) outdoor walking ability, which distinguished between 'those who could walk less than $1 \mathrm{~km}$ ' (that is, limited walking ability) from 'those who could walk further'. The index range from 0 to 3 , where $0=$ experienced no problems, and $3=$ experienced three problems. Most persons in our sample report having no problem (77 percent, $\mathrm{n}=540$ ), $11 \%(n=80)$ have one problem, four percent $(n=31)$ have two problems, and seven percent $(n=48)$ have three problems. The analyses were conducted with a dichotomized variable; $0=$ experienced no problems, $1=$ experienced $1-3$ problems.

The following variables are entered in the analyses because they are known to influence loneliness:

Respondent's age is defined as the number of complete years lived at the time of interview.

Gender is coded $0=$ male and $1=$ female.

Partner status is measured by a dichotomy coded $1=$ married/cohabitant, and $0=$ not married/not cohabitant (including those who are divorced/separated or widowed).

Educational level is categorized as 1=primary school, $2=$ secondary school, and $3=$ college/university level.

Subjective health is assessed by the question "How would you best describe your current health?" Answer categories range from $1=$ excellent to $5=$ poor. As few respondents describe their health as "excellent" or "poor", using the variable as an ordinal variable is not an option. The results produced by a variable with three categories; "very good" [1,2], "good" [3], and "poor" $[4,5]$ were much the same as the results produced with a dichotomous variable. In the analyses, we thus apply a dichotomous health variable where the self reported health evaluations "excellent", "very good", and "good" health is classified as "good health", while self reported "fair" and "poor" health are classified as "poor health". (Subjective health is often measured by these or similar adjectives. As personal assessments they do not denote clear categories, but indicate ordinal arranged evaluations. This dichotomization arranges those assessing their health in the upper part of the Likert scale (1-3) as being in "good" health and those assessing their health in the lower part of the scale (4 or 5) as being in "poor" health.)

The measures of loneliness and subjective health are from the telephone interview. Age, partner status and education are data from public registries (Statistics Norway), added with the respondents' informed consent. Five of the questions about personal mastery are from the postal questionnaire, two are from the telephone interview.

\section{Analyses}

We use both cross-sectional and longitudinal analyses. The analyses begin with a descriptive analysis of loneliness at T1 in the two groups under study, those with functional impairment and those without functional impairments. Next, bivariate analyses are conducted. We explore the bivariate associations between loneliness and the independent variables measured at $\mathrm{T} 1$. Then, multivariate analyses follow, assessing the relative significance of the independent variables (measured at T1) for the risk of loneliness at T1, and the risk for loneliness at T2, prospectively.

Associations between loneliness and the independent variables (age, gender, partner status, education, subjective health, and mastery) at $\mathrm{T} 1$ are tested using chi square tests and analysis of variance (ANOVA). Multivariate logistic regression is applied to assess the relative significance of the independent variables for risk of loneliness. For all analyses, p-values smaller than 0.05 were considered to be statistically significant.

To determine whether differences (in age, gender, partner status, education, subjective health, and mastery) between those with and those without impairments are statistically significant, we estimated separate interaction models. Interaction effects were tested entering one pair of predictors at a time in the regression equations.

\section{RESULTS}

At T1, 28 percent reported having impairments while 72 percent had no impairments. Those with impairments were significantly more often lonely than those without impairments (chi square $=15.095, \mathrm{df}=1$, $\mathrm{p}<0.001$ ). Among those with impairments, 42 percent reported loneliness. Among those without impairments, 26 percent reported loneliness.

Table 1 displays respondent characteristics like socio-demographic and health variables at T1 and their associations with loneliness among those with impairments and among those without impairments.

At T1, 72 percent of the respondents with impairments were women, 44 percent were married or cohabitant. The most common level of education was primary school (45 percent), and the majority (67 percent) reported that their subjective health was poor. The mean age of the respondents with impairments was 73.2 years $(\mathrm{SD}=3.7)$, and the mean level of mastery was $21.9(\mathrm{SD}=5.0)$.

Old age was significantly associated with loneliness among those with impairments. Women were more often lonely than men. The prevalence of loneliness is strongly associated with partner status, not having a partner was associated with loneliness. Educational level was associated with loneliness. Those with low and those with high education were more often lonely than those with education on secondary school level. Poorer subjective health was not significantly associated with loneliness among those with impairments. 
Table 1. Characteristics of the sample (percent/Mean [SD]), the association of those characteristics with loneliness (percent), and chi square-tests/analysis of variance (ANOVA) showing the association of each variable with loneliness at $\mathrm{T} 1(\mathrm{~N}=699)$.

\begin{tabular}{|c|c|c|c|c|}
\hline & \multicolumn{2}{|c|}{ Without impairments } & \multicolumn{2}{|c|}{ With impairments } \\
\hline & $\%$ & Feeling lonely & $\%$ & Feeling lonely \\
\hline Gender & & $* * *$ & & $*$ \\
\hline Men & 54 & 20 & 28 & 30 \\
\hline Women & 46 & 34 & 72 & 47 \\
\hline Partner status & & $* * *$ & & $* * *$ \\
\hline Unmarried & 35 & 49 & 56 & 54 \\
\hline Married/Cohabitant & 65 & 14 & 44 & 27 \\
\hline Education & & & & $*$ \\
\hline Primary school & 25 & 27 & 45 & 52 \\
\hline Secondary school & 51 & 24 & 41 & 31 \\
\hline College/University & 24 & 29 & 14 & 46 \\
\hline Subjective health & & $*$ & & \\
\hline Good & 83 & 24 & 33 & 34 \\
\hline Poor & 17 & 36 & 67 & 46 \\
\hline Continuous independent variables & Mean (SD) & F-statistic & Mean (SD) & F-statistic \\
\hline Age at $T 1(n=540)$ & $71.9(3.4)$ & .423 & $73.2(3.7)$ & $3.957 *$ \\
\hline PMS sumscore $(n=450)$ & $24.1(4.4)$ & $23.649 * * *$ & $21.9(5.0)$ & $8.774 * *$ \\
\hline Total $(\mathrm{N})$ & $100(540)$ & $26(141)$ & $100(159)$ & $42(67)$ \\
\hline
\end{tabular}

Those with high levels of mastery are less lonely than those experiencing lower levels of mastery.

At T1, 46 percent of those without impairments were women, 65 percent were married or cohabitant. The most common level of education was secondary school $(51 \%)$. The mean age was 71.9 years $(\mathrm{SD}=3.4)$ and the mean level of mastery was $24.1(\mathrm{SD}=4.4)$.

Among those without impairments, age was not associated with loneliness. Women were more often lonely than men. The prevalence of loneliness is strongly associated with partner status. Not having a partner was associated with loneliness. Educational level was not associated with loneliness, but poor subjective health was. Those with high levels of mastery are less lonely than those experiencing lower levels of mastery.

Multivariate logistic regression was used to assess which of the variables were independently related to loneliness at $\mathrm{T} 1$ and at $\mathrm{T} 2$, among those with impairments and among those without impairments (Table 2). Table 2 shows that among those with impairments, loneliness at T1 (2002/3) was independently associated with partner status (not being married). Also, loneliness was associated with low perceived mastery.

Prospectively, at T2 (2007/8), the only factor at T1 predicting loneliness at $\mathrm{T} 2$ among people with impairments was low perceived mastery.

Among those without impairments (like those with impairments), loneliness at $\mathrm{T} 1$ was independently associated with partner status (not being married). Education was related to loneliness: Persons with education on college/university level were most likely to be lonely, significantly more lonely than those with primary school level education. Also low perceived mastery was significantly associated with loneliness.

Prospectively, at T2, only two factors; not being married/cohabitant and low perceived mastery, predicted loneliness.

Age, gender and subjective health were not significantly associated with loneliness, neither in the crosssectional nor in the prospective analyses, in any of the two groups studied.

In ancillary analyses including the total sample (both those with and those without impairments), interactions between the impairments variable and the variables age, gender, partner status, education, subjective health, and mastery were conducted, one pair at a time. None of the variables interacted significantly with the impairments variable.

\section{DiscuSSION}

The study shows that mastery is the only factor having a significant influence both at $\mathrm{T} 1$ and $\mathrm{T} 2$ for both older people with impairments and for those without. Controlling for other factors, we find that mastery and loneliness are negatively related, which is in accordance with the main tendency in previous studies. Those older people experiencing high levels of mastery are less likely to be lonely at $\mathrm{T} 1$ and (prospectively) at $\mathrm{T} 2$. Both among people with impairments and among people without impairments high levels of mastery are significant to avoid loneliness.

Among these older people, age is not related to loneliness in the two groups. Neither has gender any 
Table 2. Multivariate logistic regressions of loneliness at T1 and T2 according to impairment status; persons 67-79 years.

\begin{tabular}{lccccccc}
\hline & \multicolumn{3}{c}{ Without impairments (n=445) } & \multicolumn{2}{c}{ With impairments (n=118) } \\
\cline { 2 - 7 } & \multicolumn{2}{c}{ Loneliness at T1 } & \multicolumn{2}{c}{ Prospectively, } & loneliness at T2 & Loneliness at T1 & Prospectively, \\
loneliness at T2
\end{tabular}

influence. Also subjective health has no influence on loneliness in the two groups, controlling for other factors. The finding that subjective health has no influence in the two groups is contrary to many other studies. In the group of our study, aged 67-79 years, most people will have reduced health and probably also will expect this to occur. The deviating results from other studies concerning subjective health may be caused by our inclusion of mastery. However, even when not including mastery, those in poor subjective health are not significantly more lonely than those in good health. Impairments as measured here implicate health induced restrictions both in daily activities and mobility restrictions that may reduce possibilities for social contact, and thus be more influential on loneliness than subjective health (50).

Mastery is a subjective way of reacting to circumstances of life, and to the ageing processes. Seeing oneself as still able to handle challenges and problems, being able to decide for oneself what to do, and being in control of life even when health and strength deteriorate, are important for all - also to prevent loneliness. But, over time, mastery seems to be even more important for those with most impairments. Thus, high levels of personal mastery prevent loneliness among older people, while age, subjective health, and gender have no significant influence.

The most significant threat for becoming lonely in old age (in both groups) is losing one's wife, husband, or partner - regardless of experienced functional health. Partner status being married/cohabitant, is the most important factor (highest odds at T1) but it is not of (protective) significance for older people with impair- ments from T1 to T2, only mastery is. A relevant question would be if the long term significance of mastery is even larger for people with impairments than for others. This should be explored in future studies.

Educational attainment is not associated with loneliness among people with impairments, but is independently associated with loneliness at $\mathrm{T} 1$ among people without impairments. Those with college/university level education are most likely to be lonely, whereas those with primary school level are least likely to be lonely at T1. These findings are not in accordance with previous studies, that are indicating more loneliness among persons with lower education $(3,11)$. The association is not found in the bivariate analysis, but appears when the other variables in our analysis are taken into consideration. Ancillary analyses not shown here (multiple regressions with various combinations of the variables included in our statistical model) indicate that educational level reaches significance when all other variables are controlled for. People with college/university level education in this study are more likely to be lonely than those with lower (primary school) education due to differences in other aspects.

Why older people with college/university level education (and without impairments) are more likely to be lonely than those with primary school education, seems to call upon a compound explanation. Persons with low education in our sample might be a more select group than persons with higher education. Some reasons are factors like poor health and functional ability, but also factors related to motivations to participate in surveys. To participate in interviews people need to have some generalized trust in other people, and trust 
is related to education (e.g. 51,52,53). Further, the level of education is associated with other variables. While some studies have shown that higher education is associated with less loneliness $(3,7,9)$, our results indicate that the association may be different when taking into account all causal influences. Education may be related to higher levels of mastery, better health and better chances of being married or cohabitant. Our results, including people near retirement age and older, may point at transient loneliness reactions to loss of colleagues and social inclusion, especially among healthy people with high education, to whom social confirmation of competence may be important for self-esteem.

Prospectively, five years later (T2), no significant association was found between educational level and loneliness among older people without impairments. Among older people with impairments, educational attainment is not significantly associated with loneliness, when other variables are controlled for.

Different definitions of loneliness, different methods of measuring loneliness, and varying and selected loss of respondents in different age groups influence the results in loneliness studies. Usually, loneliness is higher among those "lost" respondents, they are more fragile, sicker, are more often widowed, and more often institutionalized, factors increasing the risk of experiencing loneliness (54). Also, predisposing factors like personality and special personal circumstances may influence loneliness, may be more among people with stronger loneliness than among those with weaker loneliness.
One limitation concerning our study may be the small sample of people with impairments. The selected nature of our sample both at T1 and T2 (although usual in longitudinal studies) restricts generalizations to the whole population. The experience of loneliness and the associations with various life events may differ among respondents from less socially advantaged groups; people in advanced age and very frail people with many impairments and diagnoses, or those living in institutions.

To conclude, two factors in our study are particularly significant in order to prevent loneliness among older people: high levels of perceived personal mastery and having a partner. While having a partner protects against loneliness both at $\mathrm{T} 1$ and prospectively at T2 among those without impairments, the protective function is found only at T1 among those with impairments. Mastery, on the other hand, protects against loneliness at both times in both groups.

\section{ACKNOWLEDGEMENTS}

We thank Marijke Veenstra, Knut Engedal and the anonymous reviewer for their fruitful comments. The NorLAG and LOGG surveys are financed by the Research Council of Norway (grant no. 149564 and 168373), Ministry of Health and Care Services, Ministry of Labour, Ministry of Children, Equality and Social Inclusion, Ministry of Local Government and Regional Development, Norwegian Social Research (NOVA) and Statistics Norway. The LOGG and NorLAG datasets are part of the ACCESS Life Course infrastructure project funded by the National Financing Initiative for Research Infrastructure at the Research Council of Norway (grant no. 195403) and NOVA.

\section{REFERENCES}

1. Peplau LA, Perlman D, editors. Loneliness. A sourcebook of current theory, research and therapy. New York: John Wiley and Sons, 1982.

2. Strömback J, Malkan HE. Att uppleva ensamhet i samband med kronisk sjukdom. En litteratur-studie [Experiencing loneliness in connection with having a chronical disease. A literature review]. Luleå: Institutionen för hälsovetenskap, Luleå Tekniska Universitet, 2003.

3. Savikko N, Routasalo P, Tilvis RS, Strandberg TE, Pitkälä KH. Predictors and subjective causes of loneliness in an aged population. Arch Gerontol Geriatr 2005; 41 (3): 223-33.

4. Rokach A, Lechcier-Kimel R, Safarov A. Loneliness of people with physical disabilities. Soc Behav Pers 2006; 34 (6): 681-700.

5. Balandin S, Berg N, Waller A. Assessing the loneliness of older people with cerebral palsy. Disabil Rehabil 2006; 28 (8): 469-79.

6. Korporaal M, van Groenou MB, van Tilburg T. Effects of own and spousal disability on loneliness among older adults. J Aging Health 2008; 20 (3): 306-25.

7. Theeke LA. Predictors of loneliness in U.S. adults over age sixty-five. Arch Psychiatr Nurs 2009; 23 (5): $387-96$.

8. Theeke LA. Sociodemographic and health-related risks for loneliness and outcome differences by loneliness status in a sample of U.S. older adults. Res Gerontol Nurs 2010; 3 (2): 113-25.

9. Hawkley LC, Hughes ME, Waite LJ, Masi CM, Thisted RA, Cacioppo JT. From social structural factors to perceptions of relationship quality and loneliness: The Chicago Health, Aging, and Social Relations Study. $J$ Gerontol B Psychol Sci Soc Sci 2008; 63B (6): S375-S84.

10. Kaasa K. Loneliness in old age: Psychosocial and health predictors. Norsk Epidemiologi 1998; 8 (2): 195-201.

11. Pinquart M, Sörensen S. Risk factors for loneliness in adulthood and old age - A meta-analysis. Adv Pschol Res 2003; 19: 111-43. 
12. Heylen L. The older, the lonelier? Risk factors for social loneliness in old age. Ageing \& Society 2010; 30: 1177-96.

13. Havens B, Hall M, Sylvestre G, Jivan T. Social isolation and loneliness: Differences between older rural and urban Manitobans. Can J Aging 2004; 23 (2): 129-40.

14. Alpass FM, Neville S. Loneliness, health and depression in older males. Aging Ment Health 2003; 7 (3): $212-6$.

15. Cacioppo JT, Hawkley LC, Crawford E, Ernst JM, Burleson M, Kowalewski RB, et al. Loneliness and health: potential mechanisms. Psychosom Med 2002; 64: 407-17.

16. SSB 2011. Statistisk årbok 2011 (Statistical yearbook of Norway 2011). Statistics Norway <http://www. ssb.no/aarbok/saa_2011.pdf> Retrieved May 7, 2012.

17. Veenstra M. Lengre liv - bedre helse? (Longer life - better health?) In: Daatland SO, Veenstra M, editors. Bærekraftig omsorg? Familien, velferdsstaten og aldringen av befolkningen (Sustainable care? The family, the welfare state and the ageing population). Oslo: NOVA, 2012.

18. De Jong Gierveld J. A review of loneliness: Concepts and definitions, determinants and concequences. Rev Clin Gerontol 1998; 8: 73-80.

19. Pinquart M, Sörensen S. Influence on loneliness in older adults: A meta-analysis. Basic Appl Soc Psychol 2001; 23: 245-66.

20. Tornstam L. Ensamhetens ansikten. En studie av ensamhetsupplevelser hos svenskar 15-80 år [The faces of loneliness. A study of loneliness experiences in Swedes aged 15-80 years]. Uppsala: Sociologiska institutionen, 1988.

21. Tornstam L, Rydell M, Vik I, Öberg E. Ensamheten i Sverige 1985-2008 [Loneliness in Sweden 1985-2008]. Uppsala: Sociologiska institutionen, 2010.

22. Victor CR, Yang K. The prevalence of loneliness among adults: a case study of the United Kingdom. $J$ Psychol 2012; 146 (1-2): 85-104.

23. Andersson L. Interdisciplinary study of loneliness - with evaluation of social contacts as a means towards improving competence in old age. Acta Sociol 1982; 25 (1): 75-80.

24. Barstad A. Få isolerte, men mange er plaget av ensomhet [Few are isolated, but many are tormented by loneliness]. Samfunnsspeilet 2004; 18 (5): 19-26.

25. Thorsen K. Ensom og alene, sammen og lykkelig? Ensomhet i ulike aldersgrupper [Lonely and alone, together and happy? Loneliness in different age groups]. Oslo: Norsk gerontologisk institutt. NGI-Rapport 21990, 1990.

26. Jylhä M. Old age and loneliness: Cross-sectional and longitudinal analyses in the Tampere Longitudinal Study on Aging. Can J Aging 2004; 23 (2): 157-68.

27. Victor CR, Scambler SJ, Marston L, Bond J, Bowling A. Older people's experiences of loneliness in the UK: Does gender matter? Social Policy and Society 2005; 5 (1): 27-38.

28. Cohen-Mansfield J, Shmotkin D, Goldberg S. Loneliness in old age: longitudinal changes and their determinants in an Israeli sample. Int Psychogeriatr 2009; 21 (6): 1160-70.

29. Stack S. Marriage, family and loneliness: A cross-national study. Sociol Perspect 1998; 41 (2): 415-32.

30. Cohen-Mansfield J, Parpura-Gill. Loneliness in older persons: a theoretical model and empirical findings. Int Psychogeriatr 2007; 19 (2): 279-94.

31. Jacobs RJ, Kane M, N. Correlates of loneliness in midlife and older gay and bisexual men. J Gay Lesbian Soc Serv 2012; 24 (1): 40-61.

32. Dykstra PA, Van Tilburg T, De Jong Gierveld J. Changes in older adults loneliness: results from a seven-year longitudinal study. Res Aging 2005; 27 (6): 725-47.

33. Tijhuis MAR, De Jong Gierveld J, Feskens EJM, Kromhout D. Changes in and factors related to loneliness in older men. The Zutphen elderly study. Age Ageing 1999; 28: 491-5.

34. Holmén K, Furukawa H. Loneliness, health and social network among elderly people - a follow-up study. Arch Gerontol Geriatr 2002; 35: 261-74.

35. Aartsen M, Jylhä M. Onset of loneliness in older adults: results of a 28 year prospective study. Eur J Ageing 2011; 8: 31-8.

36. Guiaux M. Social adjustment to widowhood. Changes in personal relationships and loneliness before and after partner loss. PhD dissertation, Amsterdam: VU University, 2010.

37. Pearlin LI, Schooler C. The structure of coping. J Health Soc Behav 1978; 19 (1): 2-21.

38. Kempen GI, Ranchor AV, van Sonderen E, van Jaarsveld CM, Sanderman R. Risk and protective factors of different functional trajectories in older persons: are these the same? J Gerontol B Psychol Sci Soc Sci 2006; 61B (2): P95-P101.

39. Kempen GI, van Heuvelen MJ, van Sonderen E, van den Brink RH, Kooijman AC, Ormel J. The relationship of functional limitations to disability and the moderating effects of psychological attributes in communitydwelling older persons. Soc Sci Med 1999; 48: 1161-72. 
40. Krokavcova M, Nagyova I, van Dijk JP, Rosenberger J, Gavelova M, Middel B, et al. Mastery, functional disability and perceived health status in patients with multiple sclerosis. Eur J Neurol 2008; 15: 1237-44.

41. Gerstorf D, Röcke C, Lachman ME. Antecedent - concequent relations of perceived control to health and social support: longitudinal evidence for between-domain associations across adulthood. $J$ Gerontol B Psychol Sci Soc Sci 2010; 66B (1): 61-71.

42. Bjørshol E, Høstmark M, Lagerstrøm BO. Livsløp, generasjon og kjønn. LOGG 2007. Dokumentasjonsrapport [Life course, generation, and gender. LOGG 2007. Documentation report]. Oslo: Statistisk sentralbyrå, Notater 19/2010, 2010.

43. Cordray S, Polk K. The implications of respondent loss in panel studies of deviant behavior. J Res Crime Delinquency 1983; 20 (2): 214-42.

44. Victor CR, Grenade L, Boldy D. Measuring loneliness in later life: a comparison of different measures. Rev Clin Gerontol 2005; 15: 63-70.

45. Wenger GC. Loneliness: A problem of measurement. In: Jerrome D, editor. Ageing in modern society. London \& Canberra: Croom Helm, 1983: 145-67.

46. Routasalo PE, Savikko N, Tilvis RS, Strandberg YE, Pitkälä KH. Social contacts and their relationship to loneliness among aged people - a population-based study. Gerontology 2006; 52: 181-7.

47. Tikkainen P, Heikkinen R-L. Associations between loneliness, depressive symptoms and perceived togetherness. Aging Ment Health 2005; 9: 526-34.

48. Berg S, Mellström D, Persson G, Svanborg A. Loneliness in the Swedish aged. J Gerontol 1981; 36 (3): $342-9$.

49. Pearlin LI, Piolo MF. Personal control: some conceptual turf and future directions. In: Zarit SH, Pearlin LI, Schaie KW, editors. Personal control in social and life course contexts. New York: Springer, 2003: 1-21.

50. Bergland A, Thorsen K, Loland NW. The relationship between coping, self-esteem and health on outdoor walking ability among older adults in Norway. Ageing \& Society 2010; 30: 949-63.

51. Putnam RD. Bowling alone. The collapse and revival of American community. New York: Simon \& Schuster, 2000.

52. Vrålstad S. Mer aktive med tillit til andre [More active when trusting others]. Samfunnsspeilet 2012 (2): 14-20.

53. Warren ME, editor. Democracy and trust. Cambridge: Cambridge University Press, 1999.

54. Thorsen K, Clausen S-E. Funksjonshemning, ensomhet og depresjon: Hva betyr ensomhet for om personer med funksjonshemning opplever depresjon? [Impairments, loneliness and depression. The impact of loneliness on depression among people with impairments]. Tidsskr Nor Psykologforen 2008; 45: 19-27. 